\title{
The Transcriptional Coactivator Querkopf Controls Adult Neurogenesis
}

\author{
Tobias D. Merson, Mathew P. Dixon, Caitlin Collin, Rodney L. Rietze, Perry F. Bartlett, Tim Thomas, ${ }^{\star}$ and \\ Anne K. Voss* \\ The Walter and Eliza Hall Institute of Medical Research, Parkville, Victoria 3050, Australia
}

The adult mammalian brain maintains populations of neural stem cells within discrete proliferative zones. Understanding of the molecular mechanisms regulating adult neural stem cell function is limited. Here, we show that MYST family histone acetyltransferase Querkopf (Qkf, Myst4, Morf)-deficient mice have cumulative defects in adult neurogenesis in vivo, resulting in declining numbers of olfactory bulb interneurons, a population of neurons produced in large numbers during adulthood. $Q k f$-deficient mice have fewer neural stem cells and fewer migrating neuroblasts in the rostral migratory stream. $Q k f$ gene expression is strong in the neurogenic subventricular zone. A population enriched in multipotent cells can be isolated from this region on the basis of $Q k f$ gene expression. Neural stem cells/progenitor cells isolated from $Q k f$ mutant mice exhibited a reduced self-renewal capacity and a reduced ability to produce differentiated neurons. Together, our data show that $Q k f$ is essential for normal adult neurogenesis.

Key words: Qkf; transcription; chromatin; neural stem cells; adult neurogenesis; neuroblasts

\section{Introduction}

Adult neurogenesis takes place in discrete proliferation zones, such as the subventricular zone (SVZ) of the lateral ventricle. Neuroblasts born in the SVZ migrate to the olfactory bulbs forming the rostral migratory stream (Lois and Alvarez-Buylla, 1994) and give rise to periglomerular and granule cell interneurons in the olfactory bulb (Luskin, 1993; O'Rourke, 1996).

The continuation of zones of neurogenesis in the adult depends on the existence of neural stem cells (NSCs) within the adult brain. NSCs have the capacity to self-renew and to differentiate into multiple cell types (Reynolds and Weiss, 1992; Richards et al., 1992). Although the existence of NSC has fostered great interest because of their potential therapeutic applications in the treatment of neurological disorders (Rossi and Cattaneo, 2002), relatively few molecules are known to regulate adult NSC function in vivo. In particular, the molecular basis for the existence of neurogenesis in some areas of the adult brain, but not others, is unclear.

The flexible response of stem cells to environmental cues resulting in self-renewal and differentiation ultimately requires transcriptional regulation. Typically, DNA-binding transcription factors regulate multiple processes in different cell types. For

\footnotetext{
Received 0ct. 27, 2005; revised Aug. 23, 2006; accepted Sept. 16, 2006.

This work was supported by the Australian National Health and Medical Research Council and The Walter and Eliza Hall Institute of Medical Research. We thank E. Loza, A. Morcom, N. Ashman, S. Mihajlovic, F. Battye, and C Cowled for technical help. We gratefully acknowledge the gift of the 04 supernatant from T. Kilpatrick and the gift of pEF-Pgk-Puro from D. Huang.

${ }^{*}$ T.T. and A.K.V. contributed equally to this work.

Correspondence should be addressed to either of the following at the above address: Anne K. Voss, E-mail: avoss@wehi.edu.au; or Tim Thomas, E-mail: tthomas@wehi.edu.au.

P. F. Bartlett's and R. L. Rietze's present address: Queensland Brain Institute, The University of Queensland, Queensland 4072, Australia.

DOI:10.1523/JNEUROSCI.2247-06.2006

Copyright $\odot 2006$ Society for Neuroscience $\quad 0270-6474 / 06 / 2611359-12 \$ 15.00 / 0$
}

example, the "master control gene" for eye development, Pax6 (Gehring and Ikeo, 1999), has a multitude of functions in diverse cell types (Simpson and Price, 2002), ranging from pancreatic $\alpha$-cells (St-Onge et al., 1997) to olfactory interneurons (Hack et al., 2005). The paradox that comparatively simple DNA-binding proteins are able to regulate diverse processes in multiple cell types remains unresolved. However, recent work suggests that transcriptional coactivators and corepressors, in conjunction with DNA-binding transcription factors, direct time/space patterns of gene expression (Glass and Rosenfeld, 2000). Transcriptional coactivators form multiprotein complexes that contain enzyme subunits with chromatin-modifying activity, such as histone acetyltransferases, which are necessary to convert chromatin from a repressed to a transcriptionally active state (Berger, 2002). Conversely, the recruitment of corepressor complexes leads to gene silencing (Glass and Rosenfeld, 2000). These observations suggest that the nature of coregulatory complexes recruited to DNA by sequence-specific transcription factors determines the pattern of gene expression and hence cell phenotype.

Qkf is a MYST family transcriptional coactivator with histone acetyltransferase activity (Champagne et al., 1999; Thomas et al., 2000; Yang, 2004). We generated a hypomorphic $Q k f$ allele $\left(Q k f^{g t}\right)$, which results in a $90 \%$ reduction in the level of $Q k f$ transcripts. Using this allele, we have shown previously that $Q k f$ is required for normal embryonic development of the cerebral cortex. Qkf-deficient embryos show reduced proliferation in the ventricular zone of the telencephalon and a considerable reduction in the number of cortical plate neurons during development as well as a decrease in the number of cortical interneurons (Thomas et al., 2000). Intriguingly, Qkf-deficient adult brains contain fewer cells with cell surface characteristics, which enrich for cells capable of forming multipotent, proliferating cell colo- 
nies in vitro (Rietze et al., 2001). We hypothesized that Qkf may play a role in adult neurogenesis.

Here, we report the role of $\mathrm{Qkf}$ in adult neurogenesis. We show that Qkf has a function in establishing stem cell numbers in the SVZ, as well as an ongoing role in adult neurogenesis. We propose that the continuation of a high expression domain of Qkf in the SVZ of the lateral ventricles is an integral part of the processes regulating adult neurogenesis in this region.

\section{Materials and Methods}

Histological examination of the olfactory bulbs, volumetric assessment of olfactory bulb layers, 5-bromo-2'-deoxyuridine treatment regimens, and cell counts in the olfactory bulbs and lateral ventricle subventricular zones. Sets of serial sections of $Q k f^{g t / g t}$ mutant and sex-matched littermate controls or sex- and age-matched nonlittermate controls were generated from perfusion-fixed brains and cresyl violet stained or horseradish peroxidase stained for 5-bromo-2'-deoxyuridine (BrdU) or tyrosine hydroxylase immunoreactivity. Serial sections were analyzed microscopically, and images were taken using a compound microscope and a digital camera (Zeiss, Oberkochen, Germany). Olfactory bulb layer volumes were assessed by the method of Cavalieri, as described previously (Coggeshall, 1992; Thomas et al., 2000).

Number of glomeruli and profiles of mitral cells were counted on the medial side of the olfactory bulbs at five rostrocaudal levels evenly spaced at $\sim 400 \mu \mathrm{m}$ intervals between the most rostral cross section that incorporated all layers of the olfactory bulb and the most rostral section that contained the full extent of the rhinal fissure. Profiles of periglomerular cells were counted in corresponding sections at a median level between the most rostral cross section that incorporated all layers of the olfactory bulb and the most rostral section that contained the full extent of the rhinal fissure. Tyrosine hydroxylase-positive cells were counted on corresponding sections at three rostrocaudal levels spaced at $\sim 400 \mu \mathrm{m}$.

For assessment of neuroblast migration along the rostral migratory stream into the olfactory bulbs and for assessment of newly formed olfactory bulb interneurons, mice were injected with $\operatorname{BrdU}(100 \mu \mathrm{g} / \mathrm{kg}$, i.p.) twice daily for $4 \mathrm{~d}$ and left without treatment for additional $2 \mathrm{~d}$. BrdU incorporating cell profiles were counted in the olfactory bulbs at five rostrocaudal levels spaced as described above.

For assessment of long-term BrdU label retention in SVZ cells of the lateral wall of the lateral ventricle, mice were injected twice daily with BrdU for $12 \mathrm{~d}$. Mice were weighed daily throughout this procedure. All mice tolerated this protocol, and $Q k f^{g t / g t}$ mutant mice did not react differently to controls. The mice were then left for additional $16 \mathrm{~d}$ without treatment, before perfusion-fixed brains were recovered, sectioned, and stained for BrdU immunoreactivity. BrdU-positive SVZ cells were counted at six evenly spaced rostrocaudal intervals of $\sim 200 \mu \mathrm{m}$ (postweaning animals) or $500 \mu \mathrm{m}$ (aged adults) between the cross section that contained the most rostral section of the frontal cortex and the section that contained the most rostral aspect of the fimbria hippocampi.

For differential SVZ cell counts, 600 cell profiles per long-term BrdUtreated animal in the subependymal SVZ of the lateral walls of the lateral ventricles were counted according to the marker profile $\left(\mathrm{BrdU}^{+/-}\right.$, $\mathrm{GFAP}^{+/-}$, neuroblasts; the neuroblast count includes a small percentage of neuroblasts very faintly positive for BrdU) and morphology. Cells were expressed as percentage of total number of cells counted.

Isolation of subventricular zone cells, fluorescence-activated cell sorting, proliferation, and differentiation cultures. SVZ cells were isolated and cultured essentially as described previously (Reynolds and Weiss, 1992; Rietze et al., 2001; Voss et al., 2006). In brief, the SVZ of the lateral walls of the lateral ventricles were bilaterally dissected under microscopic control avoiding white matter. The tissue pieces were incubated in pancreatin/trypsin for $30 \mathrm{~min}$ on ice as described previously (Thomas and Dziadek, 1993; Voss et al., 2006), transferred to PBS, incubated for $5 \mathrm{~min}$ at $37^{\circ} \mathrm{C}$, and mechanically dissociated. Pancreatin/trypsin was inhibited with $1 \%$ fetal bovine serum in PBS and diluted with PBS and $0.2 \%$ bovine serum albumin. Cells were collected by centrifugation and plated in NSC proliferation medium [DMEM/F12, 5 mм HEPES, 13.4 mм $\mathrm{NaHCO}_{3}$, $0.6 \%$ D-glucose, $100 \mathrm{U} / \mathrm{ml}$ penicillin, $100 \mu \mathrm{g} / \mathrm{ml}$ streptomycin, $60 \mu \mathrm{M}$ putrescine, $20 \mathrm{~nm}$ progesterone, $25 \mu \mathrm{g} / \mathrm{ml}$ insulin, $100 \mu \mathrm{g} / \mathrm{ml}$ apotransferrin, $30 \mathrm{~nm}$ selenium, $10 \mathrm{ng} / \mathrm{ml}$ bovine recombinant fibroblast growth factor 2 (FGF2), $4 \mu \mathrm{g} / \mathrm{ml}$ heparin-sodium salt, $20 \mathrm{ng} / \mathrm{ml}$ murine epidermal growth factor (EGF), $2 \mathrm{mg} / \mathrm{ml}$ bovine serum albumin fraction $\mathrm{V}]$. Under these conditions, SVZ cells form spherical, floating colonies (neurospheres). Neurospheres were dissociated for passage after $7 \mathrm{~d}$ in culture.

Fluorescence-activated cell sorting (FACS) purification of SVZ cells for peanut agglutinin (PNA) ${ }^{\text {low }} /$ heat stable antigen (HSA) ${ }^{\text {low }}$ cell surface properties was performed as described previously (Rietze et al., 2001). FACS separation of SVZ cells on the basis of high or low $\beta$-galactosidase activity reflecting $Q k f$ gene promoter activity was performed using the $\beta$-galactosidase substrate fluorescein-di- $\beta$-D-galactopyranoside (FDG) (Invitrogen, San Diego, CA). Cells were loaded with FDG by hypotonic shock as suggested by the manufacturer. The conversion of FDG was inhibited competitively after $1 \mathrm{~h}$ using $1 \mathrm{~mm}$ phenethyl $\beta$-Dthiogalactopyronoside (Sigma, St. Louis, MO). Nonviable cells were labeled with $0.5 \mu \mathrm{g} / \mathrm{ml}$ propidium iodide (Sigma). Cells were sorted on a FACSDiVa (Becton Dickinson, Mountain View, CA). Cells with low or high FITC fluorescence intensity were collected separately using wildtype cells as a control for endogenous $\beta$-galactosidase activity and nonspecific fluorescence. Subsequently, cells were plated in NSC proliferation medium to test for their ability to form neurosphere colonies.

Radioactive in situ hybridization, immunohistochemistry, immunofluorescence, and live/dead staining. Perfusion-fixed brains were postfixed in $4 \%$ paraformaldehyde overnight at $4^{\circ} \mathrm{C}$. In situ hybridization was performed using a $\left[{ }^{35} \mathrm{~S}\right] \mathrm{UTP}$-labeled $\mathrm{Q} k f$ cRNA probe as described previously (Thomas et al., 2000). Immunohistochemistry was performed as described previously (Thomas et al., 2000) using the following antibodies against tyrosine hydroxylase (P40101-0; 1:100; Pel-Freez, Rogers, AR), Ki67 (NCL-Ki67p; 1:400; Novocastra, Newcastle upon Tyne, UK), glial fibrillary acidic protein (GFAP) (MAB3402; 1:1000; Chemicon, Temecula, CA), and BrdU (010198; 1:10; Bio-Science Products, Emmembrilcke, Switzerland). $\beta$-Galactosidase histochemistry was performed as described previously (Voss et al., 1998). Whole-mount immunohistochemistry was performed essentially as described (Doetsch and AlvarezBuylla, 1996). In brief, the lateral walls of the lateral ventricles were dissected from perfusion-fixed brains and, with intervening wash steps in TBS (with or without $0.5 \%$ Triton X-100), treated with methanol, acetone, $10 \%$ preimmune serum, and incubated with anti-polysialynated neural cell adhesion molecule (PSA-NCAM) antibody (AbC0019; 1:1000; AbCys, Paris, France), and then with biotinylated secondary antibody followed by $0.3 \% \mathrm{H}_{2} \mathrm{O}_{2}$, horseradish peroxidase-coupled streptavidin, diaminobenzidine, and $\mathrm{H}_{2} \mathrm{O}_{2}$. PSA-NCAM-positive chains were traced and quantified using NIH Image analysis software, version 1.62.

Immunofluorescence was performed as published previously (Voss et al., 2000). Briefly, with intervening PBS wash steps, frozen section of brain or cells were fixed in $4 \%$ paraformaldehyde (with or without $0.1 \%$ glutaraldehyde) for $20 \mathrm{~min}$, permeabilized, and blocked in $0.1-0.3 \%$ Triton X-100 and 10\% preimmune serum in PBS for 30 min. Frozen brain sections were incubated with antibodies against $\beta$-galactosidase (460-1409; 1:500; Biogenesis, Sandown, NH), nestin (MAB353; 1:500; Chemicon), PSA-NCAM (AbC0019; 1:1000; AbCys), GFAP (MAB3402; 1:1000; Chemicon), and Ki67 (NCL-Ki67p; 1:400; Novocastra). Cells were incubated with antibodies against $\beta$-tubulin type III (G7121; 1:2000; Promega, Madison, WI), GFAP (MAB3402; 1:1000; Chemicon; or Z0334; 1:500; DakoCytomation, High Wycombe, UK), GABA (1:1000; Sigma), or glutamate (1:3000; Sigma) diluted in 10\% goat serum. Primary antibody incubations were followed with intervening PBS washes by a fluorescent label-conjugated secondary antibody (Invitrogen; Vector Laboratories, Burlingame, CA; Jackson ImmunoResearch Laboratories, West Grove, PA; Serotec, Indianapolis, IN). Nuclei were counterstained with bisbenzimide. Anti-O4 (1:10; gift from T. Kilpatrick, Howard Florey Institute, Parkville, Australia) primary antibody incubation was performed without previous permeabilization. Cell viability was quantified by calculating the percentage of total cells that metabolized the esterase substrate calcein AM and maintained membrane integrity as indicated by the absence of nuclear ethidium homodimer-1 staining. Calcein AM and ethidium homodimer-1 (Invitrogen) were used at 0.25 and $2 \mu \mathrm{M}$, respectively. 

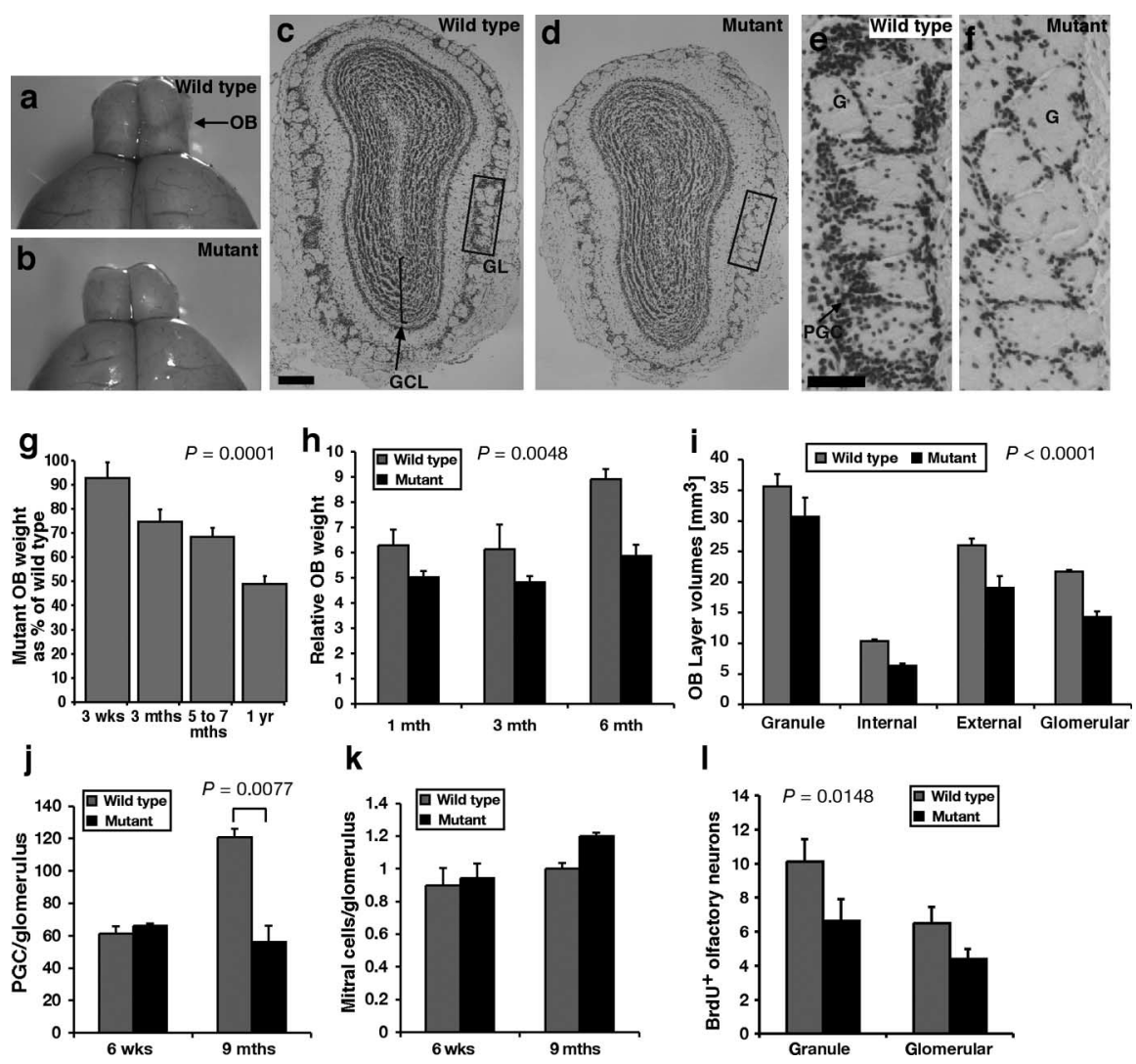

Figure 1. Qkf ${ }^{g t / g t}$ mutant mice fail to generate normal numbers of olfactory interneurons during adult life. $\boldsymbol{a}, \boldsymbol{b}$, Macroscopic appearance of wild-type sex-matched littermate controls $(\boldsymbol{a})$ and $Q k f^{\text {gt } / g t}$ olfactory bulbs (b). $\boldsymbol{c} \boldsymbol{- \boldsymbol { f }}$, Cresyl violet stained histological cross section of wild-type $(\boldsymbol{c}, \boldsymbol{e})$ and $Q k f^{g t / g t}$ olfactory bulbs $(\boldsymbol{d}, \boldsymbol{f})$ at 9 months of age. All layers are present and the neuropile is not significantly affected by the $Q k f$ mutation $(\boldsymbol{c}, \boldsymbol{d})$. However, note the marked decrease in the number of periglomerular cells in the $Q k f^{g t / g t}$ mutant ( $\left.\boldsymbol{f} \vee \boldsymbol{e} \boldsymbol{e}\right) \cdot \boldsymbol{g}, \boldsymbol{h}$, Quantification of the weight development of $Q k^{g t / g t}$ olfactory bulbs throughout adult life expressed as percentage of sex-matched littermate controls $(\boldsymbol{g})$ or relative to the total brain weight minus weight of the olfactory bulbs $(\boldsymbol{h})$. Note the progressive decrease of the weight of the $Q \mathrm{kf}^{\mathrm{gt} / \mathrm{gt}}$ olfactory bulbs with increasing age relative to controls $(\boldsymbol{g})(p=0.0001$; $n=20$ pairs of $Q k^{g t / g t}$ mutant and 22 pairs of control olfactory bulbs) and the significant difference relative to other brain

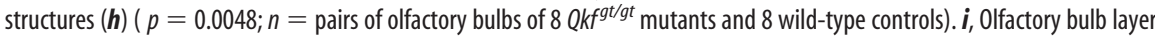
volumes assessed by the method by Cavalieri, as described previously (Coggeshall, 1992; Thomas et al., 2000). The volume of all layers was reduced similarly in the $Q k^{f^{t / g t}}$ mutants $(i)\left(p<0.0001 ; n=3\right.$ pairs of 9-month-old $Q k f^{g t / g t}$ mutant and control olfactory bulbs). $\boldsymbol{j}, \boldsymbol{k}$, Periglomerular cell numbers (PGC) (j) and mitral cell numbers ( $\boldsymbol{k}$ ) relative to numbers of glomeruli in 6-week-old and 9-month-old Qkf ${ }^{\text {tt/gt }}$ mutants compared with sex-matched littermate wild-type controls. Note that the number of mitral cells, which are formed during prenatal neurogenesis, per glomerulus does not change with age and is not different between $Q k^{\prime g t / g t}$ and wild-type controls $(\boldsymbol{k})$. In contrast, the number of periglomerular cells, which are continually produced during adult neurogenesis, per glomerulus is the same in young adult $Q k^{f t / g t}$ as in control mice, but subsequently in mature adult mice is reduced by more than one-half in the $Q \mathrm{kf}^{g t / 9 t}$ mutants compared with controls $(j)\left(p=0.0077 ; n=3 Q \mathrm{kf}^{\mathrm{gt} / g \mathrm{t}}\right.$ mutants and 3 controls at each time point). I, Quantification of newly formed, BrdU-positive neurons in Qkf $f^{g t / g t}$ and wild-type control olfactory bulbs. Note the significant reduction in newly formed neurons in the Qkf ${ }^{g t / g t}$ compared with controls $(I)$ ( $p=0.0148 ; n=410$ to 13-month-old $Q k^{\prime g t / g t}$ and 4 wild-type controls). Data are depicted as means \pm SEM and were analyzed by regression analysis of $Q k^{g t / g t}$ olfactory bulb weight as percentage of wild-type controls as a function of age $(\boldsymbol{g})$ or by one- $(\boldsymbol{j}, \boldsymbol{k})$ or two-factorial $(\boldsymbol{h}, \boldsymbol{i}$ I) ANOVA with genotype $(\boldsymbol{j}, \boldsymbol{k})$, genotype and age $(\boldsymbol{h})$, or genotype and layer $(\boldsymbol{i}, \boldsymbol{I})$ as the independent factors followed by Fisher's post hoc test. Granule, Internal, External, and Glomerular, Granule cell, internal plexiform, external plexiform, and glomerular layer of the olfactory bulbs; $\mathrm{GCL}$, granule cell layer; $\mathrm{GL}$, glomerular layer; $\mathrm{G}$, glomerulus; $\mathrm{PGC}$, periglomerular cell. Scale bars: $\boldsymbol{c}, \boldsymbol{d}, 200$ $\mu \mathrm{m} ; \boldsymbol{g}, \boldsymbol{h}, 50 \mu \mathrm{m}$.

Overexpression of $\mathrm{Qkf}$ in cultured cells. The full-length $Q k f \mathrm{cDNA}$ was assembled using cDNA clones identified and isolated by screening an embryonic day 14.5 (E14.5) brain cDNA library as we described previously (Thomas et al., 2000). The full-length coding sequence, which we reported previously (GenBank accession number AF222800) was then subcloned into pEF-Pgk-Puro (gift from D. Huang, The Walter and Eliza Hall Institute, Parkville, Australia) at the SalI and blunted BamHI sites. $p E F-P g k$-Puro drives expression from an elongation factor $1 \alpha$ promoter as described previously (Huang et al., 1997). The full-length $Q k f c D N A$ was also cloned into the $X b a \mathrm{I}$ and $S m a \mathrm{I}$ sites of an alternative vector, $p M E S$.
pMES drives expression from a chimeric chicken $\beta$-actin promoter/CMV immediate/early enhancer and incorporates an internal ribosomal entry site followed by green fluorescence protein coding sequences ( $G f p$ ) resulting in bicistronic expression of the inserted $Q k f c D N A$ and Gfp cDNA (Swartz et al., 2001). A total of $1 \times$ $10^{6}$ neurosphere cells at passages $4-5$ was transfected with $10 \mu \mathrm{g}$ of plasmid DNA using the Nucleofector II (Amaxa, Cologne, Germany) according to the manufacturer's instructions. After transfection, cells were cultured in NSC proliferation medium for $24 \mathrm{~h}$, and then cultured under differentiation conditions as described above. In experiments using pMES or pMES-Qkf, transfection efficiency (Gfp + cells/total cells) was assessed after an additional $24 \mathrm{~h}$ ( $48 \mathrm{~h}$ after transfection). After $5 \mathrm{~d}$ of differentiation, cells were fixed, and neurons were detected by immunocytochemistry using an anti- $\beta$-tubulin type III antibody as described above. Nuclei were counterstained with bisbenzimide. Cell counts were performed in 15 random view fields per culture. Note that the overall percentage of neurons differentiated from neurosphere cells passaged in culture is lower than from primary neurosphere cells (compare Figs. 9, 10).

Statistical data analysis. SAS StatView 5.0.1 software was used to perform one- or multifactorial ANOVAs or $\chi^{2}$ test, both followed by Fisher's post hoc tests as indicated in the figures. The default $\alpha$ value of the StatView 5.0.1 software $(5 \%)$ was used.

\section{Results}

Olfactory bulbs become progressively smaller in $Q k f^{g t / g t}$ mutant mice relative to controls

We observed smaller olfactory bulbs in adult $Q k f^{g t / g t}$ homozygous mutant mice compared with controls (Thomas et al., 2000) and Figure 1, $a$ versus $b$. Smaller olfactory bulbs could result from a number of different causes. For instance, the $Q k f^{g t / g t}$ phenotype could be attributable to a developmental dysgenesis, to a lack of elaboration of neuronal connections, to cell death or loss of neuropile after establishment of olfactory bulbs, or attributable to a defect in adult neurogenesis.

Histologically, the $Q k f^{g t / g t}$ olfactory bulbs appeared smaller, but all layers were present (Fig. 1, $c$ vs $d$; $e$ vs $f$ ). In particular, within the granule cell layer, which contains the bulk of the olfactory bulb cells, the cell density was similar between $Q k f^{g t / g t}$ mutants and controls, suggesting that the ratio of cells to neuropile is not affected by the lack of Qkf. Terminal deoxynucleotidyl transferase-mediated biotinylated UTP nick end labeling (TUNEL) staining and histological examination did not reveal any differences in the number of cells undergoing cell death in $Q k f^{\text {gt/gt }}$ mutants compared with controls ( $n=3$ pairs of $Q k f^{g t / g t}$ mutant and wild-type control olfactory bulbs at 6 weeks and 9 months of age each) (data not shown). This indicates that the reduction in the size of the olfactory bulbs is not 
attributable to increased cell death or to a major change in the ratio of neurons to neuropile.

Adult neurogenesis in the SVZ of the lateral ventricles produces interneurons, which are the most abundant cell population in the olfactory bulbs. If the $Q k f^{g t} \mathrm{mu}-$ tation affected adult neurogenesis, we would predict that the size of the olfactory bulbs of the $Q k f^{g t / g t}$ mutant mice would decline progressively relative to wild-type controls as the animals age.

At 3 weeks of age, after the initial postnatal wave of interneuron production (Luskin, 1993), the size of the $Q k f^{g t / g t} \mathrm{mu}-$ tant olfactory bulbs was not statistically different from wild-type littermate controls. However, relative to wild-type animals, there was a steady decline in the weight of the $Q k^{g t / g t}$ olfactory bulbs, so that at 1 year of age $Q k f^{g t / g t}$ olfactory bulbs were, on average, half the size of wild-type sex-matched littermate controls (Fig. $1 g$ ) ( $p=0.0001 ; n=20$ pairs of $Q k f^{g t / g t}$ mutant and 22 pairs of control olfactory bulbs). The difference in olfactory bulb weight was obvious, both, in absolute weight (Fig. $1 g$ ) and relative to the weight of other brain structures (Fig. $1 h)(p=0.0048 ; n=$ pairs of olfactory bulbs of $8 Q k f^{g t / g t}$ mutants and 8 wild-type controls). The volumes of the olfactory bulb layers were not significantly different at 6 weeks of age (data not shown). In contrast, by 9 months, the volumes of all layers in the $Q k f^{g t / g t}$ mutant olfactory bulbs were reduced (Fig. 1i) $\left(p<0.0001 ; n=3\right.$ pairs of $Q k^{g t / g t}$ mutant and control olfactory bulbs). We concluded that, although similar in size in early adulthood, as adulthood proceeds, the $Q k f^{g t / g t}$ mutant mice, unlike the wild-type controls, failed to increase olfactory bulb mass, which, in the absence of differences in cell density or cell death, is likely to represent a defect in adult neurogenesis.

\section{Granule and periglomerular interneurons are severely affected in the $Q k f^{g t / g t}$ olfactory bulbs}

Histological examination of serial sections of the olfactory bulbs showed that periglomerular interneurons are severely affected in mature age adult $Q k f^{\text {tt/gt }}$ mice (Fig. $1 c-f$ ). In 6-week-old young adult mice, no difference was seen in the number of periglomerular cells per glomerulus between the mutants and littermate controls (Fig. 1j). By 9 months of age, the $Q k f^{g t / g t}$ olfactory bulbs contained less than one-half the number of periglomerular cells per glomerulus than wild-type sex-matched, littermate control animals (Fig. $1 j)\left(p=0.0077 ; n=3 Q k f^{g t / g t}\right.$ mutants and 3 controls at each time point). In the same animals, the ratio of mitral cells, which form prenatally and not during adult life, to glomeruli did not differ significantly in $Q k f^{g t / g t}$ and control animals at either 6 weeks or 9 months (Fig. $1 k$ ). Furthermore, a significant reduction in newly formed, BrdU-positive neurons was observed in the $Q k f^{t / g t}$ mutants compared with controls, both in the granule and the glomerular layer (Fig. 1l) $(p=$ $0.0148 ; n=4 Q k f^{g t / g t}$ and 4 wild-type controls). The observed paucity of olfactory bulb interneurons extended to the tyrosine hydroxylase-positive subpopulation of periglomerular cells. In 1-year-old $Q k^{g t / g t}$ mutant mice, there was a highly significant decrease in the number of tyrosine hydroxylase-positive periglomerular cells in comparison to sex- and age-matched controls
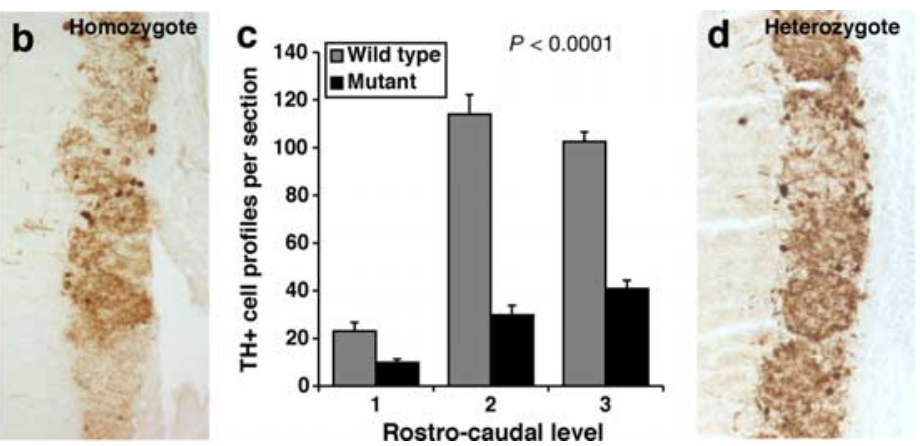

Rostro-caudal leve

.

Figure 2. Tyrosine hydroxylase-positive periglomerular cells are reduced in number in $Q k f^{g t / g t}$ mutant olfactory bulbs. $\boldsymbol{a}, \boldsymbol{b}$, Paraffin sections of sex- and age-matched wild-type $(\boldsymbol{a})$ and $Q k f^{g t / g t}$ mutant olfactory bulbs $(\boldsymbol{b})$ horseradish peroxidase( Data are depicted as means \pm SEM and were analyzed by two-factorial ANOVA with genotype and tyrosine hydroxylase-positive cells. Scale bars: $\boldsymbol{a}-\boldsymbol{c}, 50 \mu \mathrm{m}$.

(Fig. $2 a-c)\left(p<0.0001 ; n=4 Q k f^{g t / g t}\right.$ mutants and 4 controls). These results show that there is a decline with age in the granule cell and periglomerular interneuron populations in the $Q k f$ deficient animals relative to wild-type controls. As stated above, TUNEL staining and histological examination did not reveal any differences in the number of cells undergoing cell death in $Q k f^{g t / g t}$ mutants compared with controls. This indicates that the reduction in the number of olfactory bulb interneurons is not attributable to increased cell death, but rather indicates that adult neurogenesis is impaired in the $Q k f^{g t / g t}$ mutants. The observation that the olfactory bulb interneurons, which are continually formed during adult life, decline in $Q k f^{g t / g t}$ mutant mice, whereas mitral cells, which are formed prenatally, are not affected relative to the number of glomeruli, suggests that $\mathrm{Qkf}$ is required for aspects of adult neurogenesis. Heterozygous $Q k f^{g t /+}$ mutant animals exhibited a phenotype intermediate between wild-type and $Q k f^{\text {tt/gt }}$ homozygous mutants in general. Tyrosine hydroxylase staining of $Q k^{g t /+}$ heterozygous periglomerular cells is depicted as an example (Fig. 2d).

\section{$Q k f^{g t / g t}$ mutant mice have fewer neural stem cells}

Neuroblasts divide rapidly en route to the olfactory bulbs and have a cell cycle time of less than a day (Morshead and van der Kooy, 1992). In contrast, the cell cycle time of the relatively quiescent NSC in the lateral ventricle SVZ is $\sim 2$ weeks (Morshead et al., 1998). Therefore, the thymidine analog BrdU, once incorporated during DNA synthesis phase of the cell cycle, is detectable for weeks in NSC, whereas BrdU incorporated into the rapidly dividing neuroblasts is distributed to daughter cells such that it is below the level of immunodetection after three cell cycles $(<3 \mathrm{~d})$. We examined long-term BrdU label retention in SVZ cells. We injected mice with BrdU twice daily for $12 \mathrm{~d}$. The mice were then left for additional $16 \mathrm{~d}$ without treatment before perfusion-fixed brains were recovered, sectioned, and stained for BrdU immunoreactivity. Based on published cell cycle times for the relatively quiescent NSC and their rapidly proliferating progenitors (Morshead and van der Kooy, 1992; Morshead et al., 1998) and on a duration of $\mathrm{S}$ phase of $\sim 8 \mathrm{~h}$ (Nowakowski et al., 1989) and a bioavailability of BrdU for $\sim 2 \mathrm{~h}$ (Takahashi et al., 1992), this regimen should label at least one-half of all long-term label- 

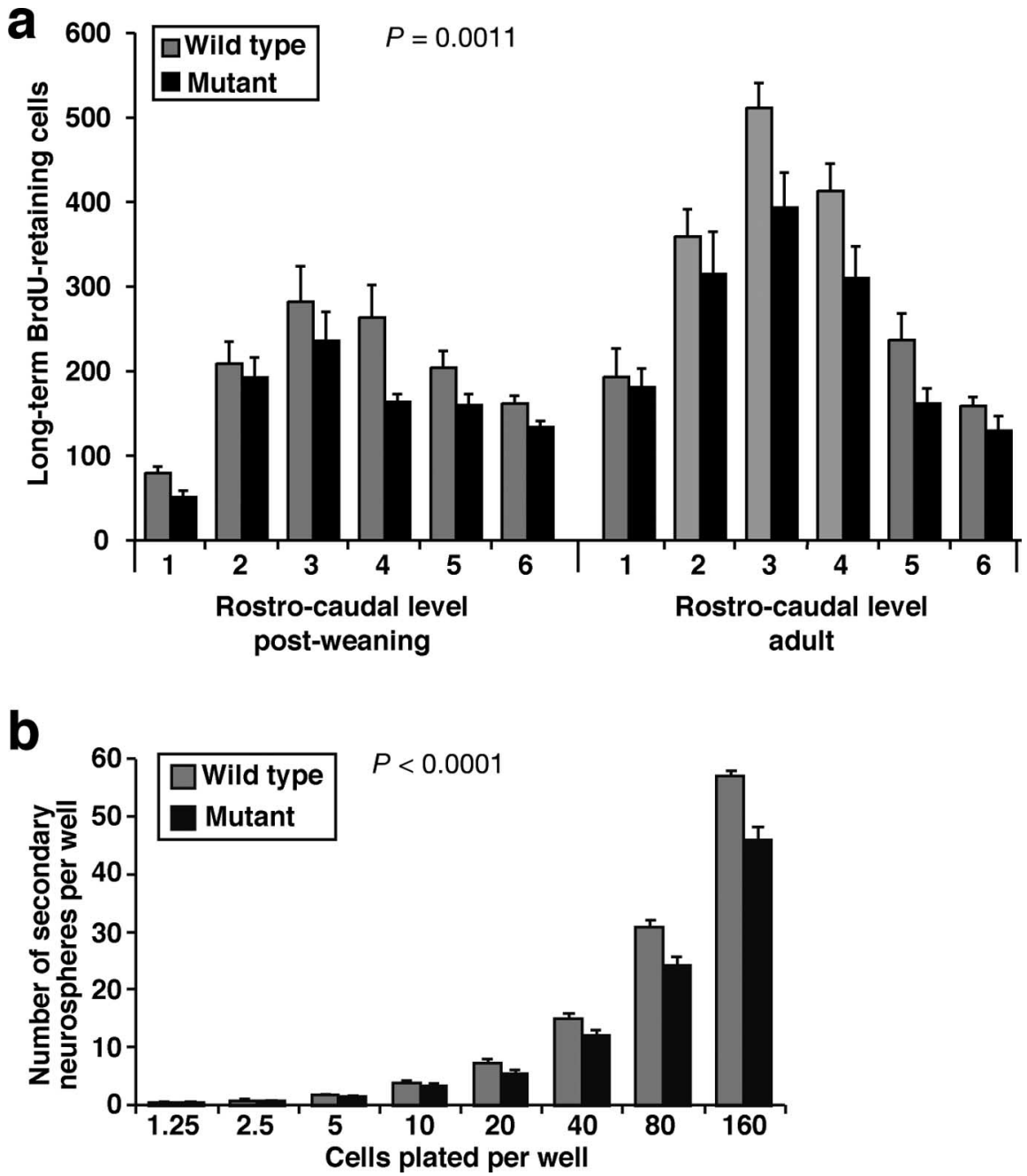

Figure 3. Qkf ${ }^{t / g t}$ mutant brains exhibit a reduction in neural stem cells in the lateral ventricle SVZ. a, Quantification of long-term BrdU label-retaining cells in the lateral ventricle SVZ. Mice were injected with BrdU twice daily for $12 \mathrm{~d}$ followed by $16 \mathrm{~d}$ without treatment before brains were perfusion-fixed, paraffin-embedded, serially cross-sectioned, and immunostained for BrdU. BrdU-positive cells in the SVZ of the lateral wall of the lateral ventricles were counted at six rostrocaudal levels. Note the consistent

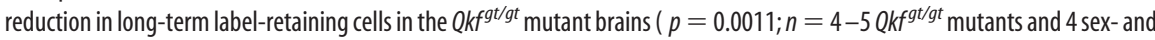
age-matched controls in each age group; postweaning, 3.5 weeks at the beginning of the 4 week experiment; adult, between 6 and 10 months old). $\boldsymbol{b}$, Quantification of self-renewal in vitro. Primary isolated SVZ cells were cultured for $7 \mathrm{~d}$ to give rise to primary neurospheres and then dissociated and passaged to 96-well plate wells at the cell number indicated. After $7 \mathrm{~d}$, the number of secondary neurospheres was counted. Note the significant reduction in the number of secondary neurospheres generated by Qkf ${ }^{\text {tt/gt }}$ mutant primary neurosphere cells compared with controls $(p<0.0001 ; n=$ neurospheres cultures isolated from 5 $Q k f^{g t / g t}$ mutant and 5 wild-type littermate control at 6 months of age). Data are depicted as means \pm SEM and were analyzed by two-factorial ANOVA with genotype and rostrocaudal level $(\boldsymbol{a})$ or genotype and cell plating density $(\boldsymbol{b})$ as the independent factors followed by Fisher's post hoc test.

retaining cells and safely avoid detection of the rapidly proliferating progenitors. Because cells, which leave the cell cycle to differentiate, migrate away from the SVZ, the long-term labelretaining cells in the SVZ represent slowly cycling stem cells. BrdU-positive SVZ cell profiles were counted on sections at six evenly spaced rostrocaudal intervals of $\sim 200 \mu \mathrm{m}$ in the postweaning animals and $500 \mu \mathrm{m}$ in the adult animals. We found a highly significant reduction (of about a quarter overall) in the number of long-term label-retaining cells in the $Q k f^{g t / g t}$ mutant animals (Fig. $3 a$ ). The reduction in long-term label-retaining cells in the $Q k f^{g t / g t}$ mutant brains was present, both per brain interval (Fig. $3 a)\left(p=0.0011 ; n=4-5 Q k f^{g t / g t}\right.$ mutants and 4 sex- and age-matched controls in each age group; postweaning, 3.5 weeks at the beginning of the 4 week experiment; adults, between 6 and 10 months of age) and per section $(p<0.0001$ and $p=0.0022$ for the postweaning and the adult age group, respectively), indicating a reduced absolute number of stem cells and a lower stem cell density in the $Q k f^{g t / g t}$ mutant brains.

SVZ cells with the surface characteristics of low peanut agglutinin binding and low heat stable antigen expression $\left(\mathrm{PNA}^{\text {low }} / \mathrm{HSA}^{\text {low }}\right.$ ) have previously been shown to contain a high proportion of the stem cell activity in the adult brain (Rietze et al., 2001). We used FACS to determine whether the number of $\mathrm{PNA}^{\text {low }} / \mathrm{HSA}^{\text {low }}$ cells is affected by lack of Qkf. The number of $\mathrm{PNA}^{\text {low }} / \mathrm{HSA}^{\text {low }}$ cells is significantly reduced in the mutant animals $(23.0 \pm 8.5$ vs $49.7 \pm 3.7 ; p=0.0467 ; n=3 Q k^{f^{t / g t}}$ mutants and 3 controls). The sorted cell populations were cultured in proliferation medium containing FGF2, EGF, and insulin to assess their ability to give rise to colonies of undifferentiated cells (neurospheres) in vitro. The number of neurosphere colonies derived from the entire $\mathrm{PNA}^{\text {low }} / \mathrm{HSA}^{\text {low }}$ sorted cell populations per brain was reduced in $Q k f^{\text {gt/gt }}$ mutants compared with controls ( $14 \pm 6$ vs $35 \pm 6$; $p=0.0303)$. The number of neurosphere colonies derived relative to the number of $\mathrm{PNA}^{\text {low }} / \mathrm{HSA}^{\text {low }}$ sorted cells was similar in $Q k f^{g t / g t}$ and controls, showing that the ability of $Q k f^{g t / g t}$ mutant PNA ${ }^{\text {low }} / \mathrm{HSA}^{\text {low }}$ cells to survive and give rise to colonies in vitro was not impaired and thus ruling out a failure of the $Q k f^{g t / g t}$ mutant cells to adapt to the cell culture conditions. Consequently, the observed reduction in primary neurosphere colony formation from $Q k f^{g t / g t}$ mutant material is attributable to the lack of colony-forming cells in vivo. Similarly, when SVZ cells were microdissected from $Q k f^{\text {gt/gt }}$ mutant and wild-type control brains and cultured directly without FACS, $Q k f^{g t / g t}$ mutant brains gave rise to significantly fewer neurosphere colonies $(356.1 \pm 77.0$ vs $582.3 \pm 97.2 ; p=$ $0.0003 ; n=7 \mathrm{Qkf}^{\text {gt/gt }}$ mutant brains and 8 control brains). The isolated cells were cultured for 16 passages and retained the capacity to form neurosphere colonies and to differentiate into neurons and glia and so exhibit some stem cell characteristics.

To examine self-renewal potential of neurosphere-forming cells, we assessed the number of secondary neurospheres that could be derived from the primary neurospheres 1 week after primary isolation from $Q k f^{g t / g t}$ mutant and control brains. Primary neurospheres derived from $Q k f^{g t / g t}$ mutant brains gave rise to significantly fewer secondary neurospheres than primary neurospheres isolated from wild-type control brains (Fig. $3 b)(p<$ $0.0001 ; n=$ neurosphere cultures isolated from $5 \mathrm{Qkf}^{\text {gt/gt }}$ mutant and 5 wild-type littermate control brains). A similar defect in secondary neurosphere formation was observed in primary neurospheres derived from FACS-sorted PNA ${ }^{\text {low }} / \mathrm{HSA}^{\text {low }}$ SVZ cells 
(data not shown). These results shows that, although the $Q k f^{g t / g t}$ mutant brain contains cells capable of generating neurospheres in vitro, each primary neurosphere contains fewer cells with the potential to generate secondary neurospheres. This suggests that $Q k f^{g t / g t}$ mutant cells have a defect in self-renewal in vitro.

\section{$Q k f^{g t / g t}$ mutant mice generate fewer neuroblasts in vivo}

To examine the relative abundance of SVZ cells involved in adult neurogenesis, we performed differential counts of the SVZ cell types [i.e., long-term BrdU labelretaining cells, which were either BrdU/ GFAP double positive (Fig. $4 a$ ) or BrdU single positive (Fig. 4b), GFAP singlepositive astrocytes (Fig. 4b), or neuroblasts (Fig. 4c)]. We found that the percentages of these cell types were unaffected by $Q k f$ mutation in young, 3.5- to 5.5week-old animals (Fig. $4 d$ ). In contrast, in animals aged 6-10 months, the percentage of neuroblasts was significantly decreased in the $Q k f^{g t / g t}$ mutants compared with controls by $\sim 20 \%$ (Fig. $4 e$ ) ( $p=$ 0.0007 ). Correspondingly, the percentage of all other cell types was increased in the $Q k f^{\text {gt/gt }}$ mutants by $\sim 20 \%$, namely $\mathrm{GFAP}+/ \mathrm{BrdU}-$ astrocytes $(p=0.0074)$, $\mathrm{GFAP}+/ \mathrm{BrdU}+$ cells $(p=0.0402)$, and GFAP $-/$ BrdU + cells $(p=0.0201)$ (Fig. $4 e)\left(n=5 Q k f^{g t / g t}\right.$ mutant and 4 wild-type control brains). Note, however, that this is a percentage increase, not an increase in the absolute number of long-term BrdU label-retaining cells, which is decreased in the $Q k f^{g t / g t}$ mutant animals as reported above and in Figure $3 a$. The neuroblasts population itself, although overall reduced in the $Q k f^{g t / g t}$ mutants, exhibited a similarly high percentage of proliferating cells as assessed by staining for the cell cycle marker Ki67 (data not shown). The significant change in the percentage of neuroblasts indicates a reduction in the total output of cells of the neuronal lineage from the $Q k f^{t / g t}$ mutant stem cell compartment.

Together, the results above show that (1) histologically, over the course of a year, $Q k f^{\text {gt/gt }}$ mutant mice show a decline in vivo specifically in cells formed during adult neurogenesis and not in cells formed by prenatal neurogenesis. (2) By BrdU labeling, $Q k f^{\text {th/gt }}$ mutant mice have fewer long-term label-retaining SVZ cells in vivo, a candidate stem cell population. (3) By differential SVZ cell count, $Q k f^{g t / g t}$ mutant long-term label-retaining cells produce fewer progeny of the neuronal lineage. (4) By FACS, $Q k f^{g t / g t}$ mutant mice have fewer SVZ cells in vivo with cell surface properties that have previously shown to be enriched for cell with stem cell characteristics. (5) By direct isolation and culture in vitro, $Q k f^{g t / g t}$ mutant mice have fewer neurosphere-forming cells capable of long-term self-renewal and differentiation into multiple brain cell types. (6) The multipotent cells isolated from
$Q k f^{g t / g t}$ mutant brains exhibit a reduced capacity for self-renewal in vitro.

\section{$Q k f$ is expressed in the neurogenic region of the subventricular zone}

If Qkf directly affected adult neurogenesis, we would expect Qkf to be expressed in the neurogenic regions of the SVZ in adult mice. To examine this question, we conducted a time course study of $Q k f$ gene expression from birth, during postnatal development and in adult animals using in situ hybridization. At birth, strong $Q k f$ gene expression was seen in the SVZ cells, the ependymal layer, the deep layers of the differentiating cortical plate and in dorsal aspects of the striatum (Fig. 5a). Between postnatal days 7-21, the high-level $Q k f$ gene expression progressively retracts to 

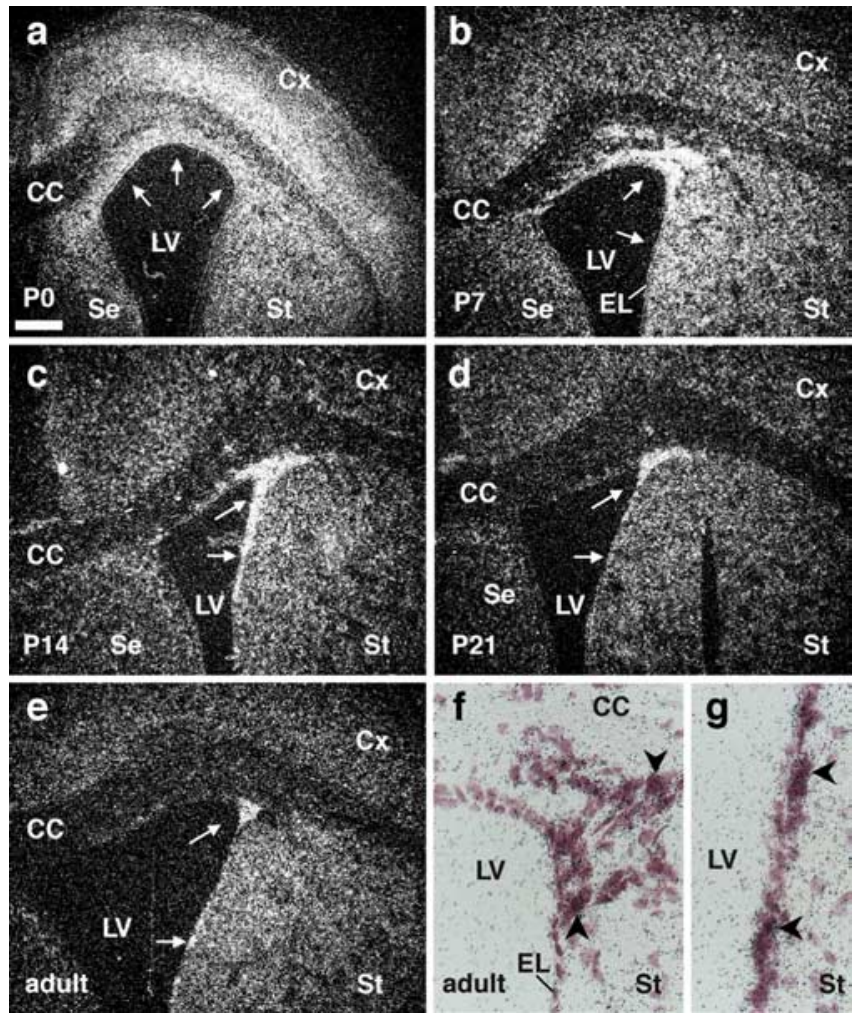

Figure 5. The high-level $Q k f$ gene expression domain denotes the neurogenic area of the lateral ventricle SVZ. $\boldsymbol{a}-\boldsymbol{g}$, Developmental series of paraffin cross sections of wild-type brains at postnatal day 0 (P0) (a), P7 (b), P14 (c), P21 (d), and adult (P84) $(\boldsymbol{e}-\boldsymbol{g})$ hybridized with a $\left[{ }^{35}\right.$ S]UTP-labeled Qkf cRNA probe as described previously (Thomas et al., 2000). Qkf mRNA is represented by precipitated silver grains, which appear white in the dark-field images $(\boldsymbol{a}-\boldsymbol{e})$ and black in the bright-field images $(\boldsymbol{f}, \boldsymbol{g})$. Note the strong expression of the $Q k f$ gene at $\mathrm{PO}$ in the cortical and striatal SVZ and in the lower layers of the cerebral cortex. This high-level Qkf expression domain becomes progressively restricted to the SVZ of the lateral wall of the lateral ventricle ( $\boldsymbol{a}-\boldsymbol{e}$, arrows) until high levels of $Q k f$ gene expression are only found in a subset of cells in the region of adult neurogenesis in the lateral wall SVZ of the lateral ventricles. Note that some cells within the adult neurogenic region exhibit high levels of Qkf mRNA ( $\boldsymbol{f}, \boldsymbol{g}$, arrowheads), whereas neighboring cells show no or low levels of Qkf mRNA. CC, Corpus callosum; $C$, cerebral cortex; EL, ependymal layer; LV, lateral ventricle; SE, septum; St, striatum. Scale bar: $\boldsymbol{a}-\boldsymbol{e}, 200 \mu \mathrm{m} ; \boldsymbol{f}, \boldsymbol{g}, 25 \mu \mathrm{m}$.

the SVZ of the lateral wall of the lateral ventricle walls (Fig. $5 b-d$ ). In the adult brain, $Q k f$ gene expression is generally low. However, a small region of high-level gene expression is retained in the SVZ of the lateral ventricle walls where neurogenesis persists throughout adult life (Fig. 5e). Within this region, $Q k f$ gene expression is heterogeneous, with some cells expressing high levels of $Q k f$ and neighboring cells expressing low levels (Fig. 5f,g).

$Q k f$ is expressed strongly in subventricular zone cells, which give rise to self-renewing neural precursor cell colonies in vitro

Because the neurogenic SVZ contains multiple cell types, Qkf could function in NSC and their progeny or in cells providing the microenvironment for NSC. To discern these possibilities, we isolated and analyzed $Q k f$-expressing cells directly from the SVZ. Activity of the lac $Z$ reporter gene, which we introduced into the Qkf locus (Thomas et al., 2000), reflected the high-level Qkf expression domain in the SVZ (compare Figs. 5, 6a). The $\beta$-galactosidase-positive region included actively proliferating cells, as shown by expression of the proliferation marker Ki67 (Fig. 6b). Using FDG, which $\beta$-galactosidase converts to fluores- cein (FITC), we monitored Qkf promoter activity in viable SVZ cells by measuring cellular FITC production by FACS. As expected, a subpopulation of SVZ cells from $Q k f^{g t /+}$ heterozygous mice expressed $\beta$-galactosidase and therefore were FITC positive, whereas wild-type cells were FITC negative (Fig. 6, $c$ vs $d$ ). When we sorted and cultured the SVZ subpopulations with low versus high FITC intensity, the fraction of SVZ cells with high $Q k f$ promoter activity yielded neurosphere colonies at a significantly higher frequency compared with unsorted wild-type control cells (Fig. 6e) $\left(\chi^{2}=158.7, \mathrm{df}=1, p<0.0001 ; n=\right.$ cell isolates from 3 $Q k f^{g t /+}$ heterozygous and 3 wild-type brains). In addition, we found that FACS purification of $Q k f^{g t /+}$ SVZ cells on the basis of high $Q k f$ promoter activity yielded a ninefold enrichment for neurosphere-forming cells over cells with low $Q k f$ promoter activity (Fig. 6e) $\left(\chi^{2}=250.1 ; \mathrm{df}=1 ; p<0.0001\right)$. Neurospheres derived from SVZ cells, sorted on the basis of high $Q k f$ promoter activity, retained the capacity for self-renewal and the ability to produce neurons and glia after at least 16 passages in vitro. This shows that $Q k f$ is expressed by long-term self-renewing, multipotent, neural precursors that conform to the definition of stem cells proposed by Morshead and van der Kooy (2004) and/or by transit amplifying cells, which may retain stem cell functions such as prolonged proliferation and multipotency when exposed to growth factors in vitro (Doetsch et al., 2002). These results indicate that $Q k f$ is expressed highly in adult NSC/transit amplifying cells and, in concert with our in vivo data demonstrating the role of Qkf in adult neurogenesis as described above, suggests that Qkf is required cell-autonomously in neural stem cells for adult neurogenesis.

\section{Cells positive for markers of neurogenic cells exhibit high levels of $Q k f$ gene activity}

To specify the cell types with high-level $Q k f$ gene activity, we examined expression of $\beta$-galactosidase from the lac $Z$ reporter gene in the $Q k f^{g t}$ locus and marker proteins of the SVZ neurogenic cell community (Fig. 7). $\beta$-Galactosidase activity was high in the SVZ of the lateral ventricles (Figs. $6 a, 7 a$ ) as well as throughout the rostral migratory stream (Fig. 7a,b). In addition, strong $\beta$-galactosidase activity was detected in the cerebral cortex (Fig. 7a,b). Cortical cells showed punctate $\beta$-galactosidase staining. In contrast, SVZ and rostral migratory stream (RMS) cells exhibited $\beta$-galactosidase activity distributed throughout the cytoplasm in addition to punctate areas of high $\beta$-galactosidase activity (Fig. $7 a, b)$. Immunofluorescence of the SVZ confirmed $\beta$-galactosidase reporter expression in the neurogenic area. Double immunofluorescence showed that all SVZ cells expressing the $\beta$-galactosidase reporter from the $Q k f^{g t}$ locus were also positive for nestin (Fig. $7 c-f$ ). A subset of the SVZ cells was positive for PSA-NCAM. PSA-NCAM marks migrating neuroblasts (Doetsch et al., 1997). These cells expressed $\beta$-galactosidase at moderate levels (Fig. $7 g-j$ ). Another subset of the SVZ cells was positive for GFAP. GFAP marks astrocytes in the subependymal subventricular zone (Doetsch et al., 1997). A small number of GFAP-positive cells were also $\beta$-galactosidase positive (Fig. $7 k-$ $n)$. Furthermore, we found that $\beta$-galactosidase expression coincided with expression of the proliferation marker Ki67 (Fig. $7 o-r)$.

These results show that the $Q k f$ gene is active at various levels in all SVZ neurogenic cells including the putative transit amplifying cells (nestin,+ GFAP-, PSA-NCAM-), the neuroblasts (PSA-NCAM +, nestin + , GFAP-), and a subset of SVZ astrocytes (GFAP + , nestin + , PSA-NCAM-), which have been proposed to be the SVZ neural stem cells (Doetsch et al., 1999). 
The number of migrating neuroblasts is reduced in $Q k f^{g t / g t}$ mutant animals If the $Q k f^{f^{t / g t}}$ mutant SVZ cell community contained a lower percentage of neuroblasts as a result of decreased output of neuroblasts from the neural stem cell compartment, we would also expect a reduction in the absolute number of neuroblasts. To investigate this prediction, we analyzed PSA-NCAM-positive migratory neuroblasts in the lateral wall of the lateral ventricles. As expected, the number of PSA-NCAM-positive migratory neuroblasts was reduced in $Q k f^{f^{t / g t}}$ mutants compared with wild-type controls (Fig. $8 a, b)$. PSA-NCAM-positive chains of migrating neuroblasts were traced (Fig. $8 c, d$ ) and quantified and showed a significant reduction in the density and extent of labeling in $Q k f^{g^{t / g t}}$ mutants (14.6 \pm 0.8 vs $23.7 \pm 1.7 \times 10^{3}$ pixels per hemisphere; $p=0.0002 ; n=$ both hemispheres of 5 $Q k f^{g t / g t}$ mutant and 6 sex- and agematched wild-type brains, 5-8 months of age), indicating a deficiency in the absolute number of migrating neuroblasts. To assess the migration of newly formed neuroblasts, we injected mice twice daily with BrdU for $4 \mathrm{~d}$ and, after an additional $2 \mathrm{~d}$ without treatment, recovered perfusionfixed brains and processed them for BrdU immunohistochemistry on transverse paraffin sections. This regimen allows labeling of proliferating neuroblasts en route to the olfactory bulbs. During the $2 \mathrm{~d}$ without BrdU treatment, the labeled cells migrate into the olfactory bulb (Lois and Alvarez-Buylla, 1994). This medium-term BrdU incorporation study showed that the $Q k f^{g t / g t}$ mutant neuroblasts did not exhibit a migration defect ( $n=310$ - to 13-month-old $Q k f^{t / / g t}$ mutants and 3 sex- and age-matched wild-type controls) (data not shown). We conclude that like NSC and olfactory bulb interneurons their intermediates, the migrating neuroblasts, are reduced in absolute numbers in adult $Q k f^{g t / g t}$ mutant brains, but migrate at a normal speed along the rostral migratory stream into the olfactory bulbs.

\section{$Q k f^{g t / g t}$ mutant neurosphere cells have a reduced capacity to form neurons}

To determine whether a cell intrinsic requirement for $\mathrm{Qkf}$ in neural stem cells/neural precursor cells contributes to the reduction in differentiated progeny, we examined the capacity for neurosphere cells to differentiate into neurons in vitro. SVZ cells were isolated from $Q k f^{g t / g t}$ mutant and wild-type brains and cultured for 1 week as primary neurospheres. The neurosphere cells were then dissociated and plated on poly-ornithine and laminin and cultured without FGF2 or EGF, but with $1 \%$ fetal bovine serum to induce differentiation as described (Rietze et al., 2001). Under these conditions, the neurosphere cells differentiate into neurons, astrocytes, and oligodendrocytes. We identified the differentiated cell types by fluorescence immunocytochemistry for neuron ( $\beta$-tubulin type III), astrocyte (GFAP), oligodendrocyte (O4) markers and cellular morphology and counted the cells to assess quantitative differences (Fig. 9a-d). Compared with wild- type cells, $Q k f^{f^{t / g t}}$ neurosphere cells gave rise to $\beta$-tubulin type III-positive neurons at a lower frequency (Fig. $9 e)\left(\chi^{2}=697.0\right.$, $\mathrm{df}=1, p<0.0001 ; n=$ differentiation cultures from $9 \mathrm{Qkf}{ }^{t t / g t}$ mutant and 9 wild-type brains for neurons) and to GFAPpositive astrocytes at a correspondingly higher frequency (Fig. $9 e)\left(\chi^{2}=122.6, \mathrm{df}=1, p<0.0001 ; n=\right.$ differentiation cultures from $8 \mathrm{Qkf}^{\mathrm{tt} / \mathrm{gt}}$ mutant and 7 wild-type brains for astrocytes). A similar number of O4-positive oligodendrocytes was produced by mutant and control cells (Fig. $9 e$ ). Similarly, $Q k f^{g t / g t}$ mutant neurospheres gave rise to fewer neurons than controls when differentiated without previous cell dissociation (supplemental Fig. 1 , available at www.jneurosci.org as supplemental material). Cell viability was similar and very high in $Q k f^{t / / g t}$ mutant and control cultures, indicating that the reduction in $Q k f^{g t / 8 t}$ neuronal progeny was not attributable to cell death (supplemental Fig. 1, available at www.jneurosci.org as supplemental material). Furthermore, the neuronal differentiation defect was not restricted to a specific neuronal subtype, because all wild-type and $Q k f^{\text {tt/gt }} \mathrm{mu}$ tant neurosphere-derived neurons were immunopositive for GABA, consistent with their primary role in generating interneurons in the olfactory bulbs, as well as glutamate, which is a precursor of GABA apart from its role as a neurotransmitter in glutamatergic neurons (supplemental Fig. 2, available at www.jneurosci.org as supplemental material).

\section{Overexpression of $Q k f$ in wild-type and $Q k f^{t / g t}$ mutant cells results in increased neuron production}

We have shown above that Qkf deficiency leads to a reduction of neuron production in vivo and in vitro. To test whether the con- 

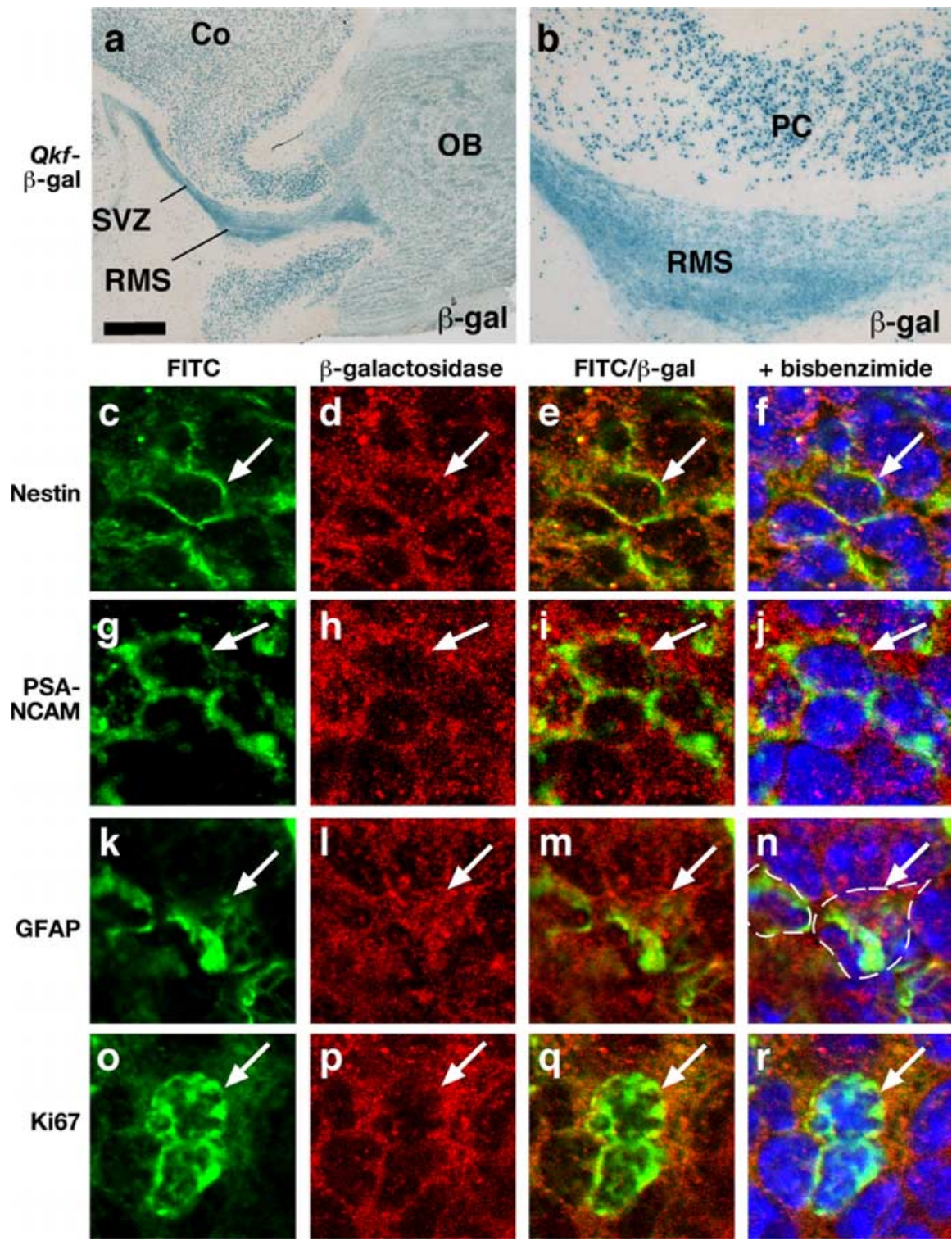

Figure 7. SVZ neurogenic cells exhibit high levels of $Q k f$ gene activity. $\boldsymbol{a}, \boldsymbol{b}$, Frozen parasagittal $Q k f^{g t /+}$ brain sections of the lateral ventricle SVZ neurogenic area and the RMS reacted for $\beta$-galactosidase activity (blue) encoded by a lacZ reporter gene inserted into the $Q k f$ locus in the $Q k^{g t}$ allele. Note strong $\beta$-galactosidase activity distributed throughout the cytoplasm in all SVZ cells, diffuse cytoplasmic $\beta$-galactosidase activity in olfactory bulb cells $(\mathrm{OB})(\boldsymbol{a})$ and punctate $\beta$-galactosidase activity in cells of the frontal cortex $\left(C_{0}\right)(\boldsymbol{a})$ and the piriform cortex $(\mathrm{PC})(\boldsymbol{b}) . \boldsymbol{c}-\boldsymbol{r}$, Confocal images of $Q k f^{9 t /+}$ brain cross sections immunostained for nestin, PSA-NCAM, GFAP, Ki67 labeled in green $(\boldsymbol{c}, \boldsymbol{g}, \boldsymbol{k}, \boldsymbol{o})$, corresponding colabeled $\beta$-galactosidase in red $(\boldsymbol{d}, \boldsymbol{h}, \boldsymbol{l}, \boldsymbol{p})$, red and green channels merged in $\boldsymbol{e}, \boldsymbol{i}, \boldsymbol{m}, \boldsymbol{q}$ and $\boldsymbol{f} \boldsymbol{j}, \boldsymbol{n}, \boldsymbol{r}$ overlaid with bisbenzimide nuclear counterstain in blue. Cells double positive for $\beta$-galactosidase and one of the markers appear yellow in areas in which both proteins colocalize in the cytoplasm; $\beta$-galactosidase/Ki67 double-positive cells $(\boldsymbol{q})$ exhibit a green nucleus with a thin rim of yellow cytoplasm reflecting the non-nuclear localization of $\beta$-galactosidase and the predominantly nuclear localization of Ki67. The perimeter of cells positive for GFAP and $\beta$-galactosidase is marked with a stippled line in $\boldsymbol{n}$. Double-positive cells are indicated (arrow). Scale bar: $\boldsymbol{a}, 512 \mu \mathrm{m} ; \boldsymbol{b}, 128 \mu \mathrm{m}$; $\boldsymbol{c}-\boldsymbol{f}, \boldsymbol{g}-\boldsymbol{j}, \boldsymbol{k}-\boldsymbol{n}$, and $\boldsymbol{o}-\boldsymbol{r}, 21,18,20$, and $19 \mu \mathrm{m}$, respectively.

verse was also true, namely whether elevated levels of Qkf could enhance neuron production, we overexpressed $Q k f$ in wild-type and $Q k f^{g t / g t}$ mutant neurosphere cells in vitro using two different overexpression plasmids as well as empty vector controls (Fig. $10)$. We observed that overexpression of $Q k f$ in wild-type cells led to an increase in the number of neurons differentiating from neurosphere cells in vitro. The number of neurons was increased 2.8-fold over untransfected wild-type cells (experiment 1) (Fig. 10c) $(p=0.0006)$ and 4.2-fold over wild-type cells transfected with empty vector (experiment 2) (Fig. 10c) ( $p<0.0001)$. Qkf
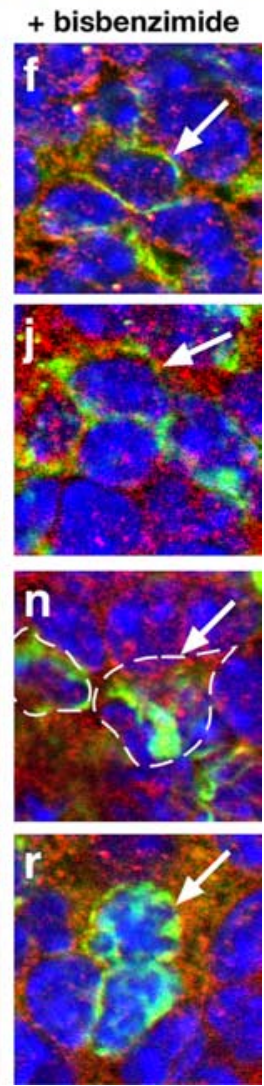

deficiency leads to a reduction in neuron production in vitro by approximately onehalf (Fig. 9). Overexpression of $Q k f$ in $Q k f^{g t / g t}$ mutant neurosphere cells resulted in a 2.4-fold increase in neuron production over $Q k f^{g t / g t}$ mutant cells transfected with empty vector (experiment 3 ) (Fig. 10c) $(p=0.0100)$. These data show that the level of neuronal differentiation is dependent on the level of $Q k f$ gene expression.

In conclusion, like the adult $Q k f^{g t / g t}$ SVZ in vivo, adult $Q k f^{g t / g t}$ neurosphere cells exhibited a reduction in their potential to form neurons, suggesting that $\mathrm{Qkf}$ is required for output of neurons in normal numbers during adulthood.

\section{Discussion}

In summary, our results show that, in the absence of normal $Q k f$ alleles, adult NSC are less abundant and produce fewer migrating neuroblasts and fewer olfactory interneurons in vivo. In addition, $Q k^{g t / g t}$ mutant neural precursor cells give rise to fewer neurons in vitro. Our data show that $\mathrm{Qkf}$ is required for two essential functions in adult neurogenesis, namely the establishment of NSC and the production of normal numbers of neurons from NSC throughout adult life.

\section{Qkf is expressed in NSC}

$Q k f$ has a dynamic pattern of expression during development that correlates with its role in cerebrocortical development (Thomas et al., 2000). Early in embryonic development, expression of $Q k f$ is low, but with the onset of cortical development expression becomes high in the telencephalon. During the neurogenic phase of development, expression is high both in the ventricular zone and in the cortical plate. High-level expression is initially found in the dorsal telencephalon but by E15.5 is also found in the ventral areas, especially the ganglionic eminences. Previously, we have shown that $Q k f^{g t / g t}$ mutant mice have reduced levels of proliferation in the cerebrocortical ventricular zone and substantially reduced numbers of neurons in the cortical plate during prenatal development (Thomas et al., 2000).

In our current work, we have shown that the high-level expression domain of $Q k f$ retracts to the SVZ of the lateral wall of the lateral ventricles during the postnatal to adult phase, correlating with the gradual reduction in neurogenesis in the postnatal period and maintenance of neurogenesis in the region of high-level $Q k f$ gene expression of the adult brain. The region of high $Q k f$ expression is the site of the majority of mitotic activity in the adult SVZ. The high mitotic activity in the SVZ reflects predominantly the proliferating NSC progeny, the transit amplifying cells and neuroblasts. Consistent with proposed models of NSC organization within the 
subventricular zone (Doetsch et al., 1997), we observed striking heterogeneity in $Q k f$ expression levels between adjacent cells, suggesting that $Q k f$ expression levels may correlate with cellular identity. $Q k f$ gene activity correlates with the expression of markers of proliferative neurogenic cells such as nestin, PSA-NCAM, and Ki67. Qkf gene activity was also observed in a fraction of GFAP-positive SVZ cells. Because $Q k f$ gene activity was observed in multiple neurogenic cell types, it was important to determine whether high $Q k f$ expression was present in NSC, their progeny, or in supporting cells (which would suggest that the phenotype is attributable to an indirect effect of Qkf on the stem cell niche). We have shown by FACS analysis of a $\beta$-galactosidase marker inserted into the Qkf locus that cells with stem cell characteristics express $Q k f$ and that stem cell activity is enriched in the $Q k f$-expressing cell fraction. Apart from the SVZ, the dentate gyrus, the other forebrain neurogenic zone, also expresses the $Q k f$ gene strongly during development and in the adult (Thomas et al., 2000) (T. Thomas, T. D. Merson, and A. K. Voss, unpublished observations).

$Q k f$ is required for normal numbers of neural stem cells

We observed a reduced number of primary neurosphere colonies generated from $Q k f^{g t / g t}$ mutant compared with wild-type animals. Although the precise in vivo identity of the cells that generate neurospheres in vitro remains controversial (Doetsch et al., 2002; Morshead and van der Kooy, 2004), significant evidence supports the principle that neurosphere formation from the adult SVZ correlates with NSC activity in vivo (Morshead et al., 1994; Morshead and van der Kooy, 2004). Cells that retain label of DNA synthesis (tritiated thymidine or BrdU) for extended periods either have left the cell cycle after labeling or are cells that cycle very slowly. Long-term label-retaining cells in germinal layers are candidate stem cells (Potten and Morris, 1988). We found that Qkf deficiency reduced the number of long-term BrdU labelretaining SVZ cells in vivo. We observed a similar reduction in long-term BrdU label-retaining cells in the postweaning period as in 6- to 10-month-old mice, suggesting that $Q k f$ function is essential for the establishment of normal numbers of NSC, but not for the maintenance of established NSC. However, $Q k f^{g t / g t} \mathrm{mu}-$ tant primary neurosphere cells gave rise to fewer secondary neurospheres in vitro, suggesting that $Q k f^{g t / g t}$ mutant cells have a defect in self-renewal, at least in the context of an in vitro culture system.

Differential counts of the SVZ cells showed that $Q k f^{g t / g t}$ mutant long-term label-retaining cells are able to generate the same output of stem cell progeny as controls in the early postweaning phase. In sharp contrast, in aged adult animals, Qkf deficiency results in the production of fewer neuroblasts in the SVZ, indicating an ongoing requirement of $\mathrm{Qkf}$ to maintain neuronal lineage differentiation at normal productivity. The deficit in neuroblast production from $Q k f^{g t / g t}$ mutant SVZ NSC results in a continual paucity in neurons produced by adult neurogenesis, which, if it not balanced by a reduction in neuron turnover, will result in a progressive deficit in olfactory bulb interneurons. Consequently, the olfactory bulb phenotype becomes progressively worse as the animals age. Although wild-type adult NSC are able to undergo extensive proliferation after chemical or radioisotope injury to reestablish the required stem cell pool (Morshead et al., 1994; Doetsch et al., 1999), aged adult Qkf mutant NSC were unable to compensate for their lack of stem cell number. If $\mathrm{Qkf}$ was solely required for establishment of the adult NSC population and had no role in adult neurogenesis, we would predict that the stem cells present at the end of the postnatal period would proliferate to compensate for any developmental defects. In this scenario, we expect that any phenotype present in young mice would improve relative to littermate controls or, at the very least, not worsen. However, this is not the case, indicating a continued requirement for Qkf in adult neurogenesis.

We conclude that, as one would expect from ongoing $Q k f$ gene expression in stem cells, that $\mathrm{Qkf}$ is required for adult neurogenesis in the stem cell compartment. Noteworthy in this context is also that the $Q k f^{g t}$ allele produces $\sim 10 \%$ of normal $Q k f$ mRNA, and therefore the defect in adult neurogenesis was observed in the presence of residual Qkf, implying that the neurogenesis defect reported here underrepresents the full requirement of $\mathrm{Qkf}$ in adult neurogenesis.

The reduction in NSC number resulting from Qkf deficiency and the reduction in output of NSC progeny from the $Q k f$ mutant SVZ combined with our observation that the $Q k f$ gene is expressed in NSC suggests strongly that there is a functional link between the maintenance of high $Q k f$ expression from the prenatal phase through to the adult and the persistence of neurogenesis in the adult SVZ.

\section{Qkf is required for neuron production}

Mitral cells form synaptic connections with the axons of odorant receptor neurons within olfactory glomeruli (Mombaerts et al., 1996). Therefore, the number of glomeruli should, within experimental error, correlate with the number of mitral cells. Mitral cells and tufted cells are produced prenatally from the olfactory bulb ventricular zone (Hinds, 1968). No significant difference in the number of mitral cells per glomerulus was seen between $Q k f^{\text {gt/gt }}$ mutant animals and controls. In contrast, the number of interneurons, which are continually produced by adult neurogenesis, underwent significant reduction per glomerulus compared with controls as the animals aged. The failure of adult $Q k^{g t / g t}$ mutant brains to generate normal numbers of interneurons in vivo and the inability of $Q k f^{g t / g t}$ neurosphere cells to gen- 

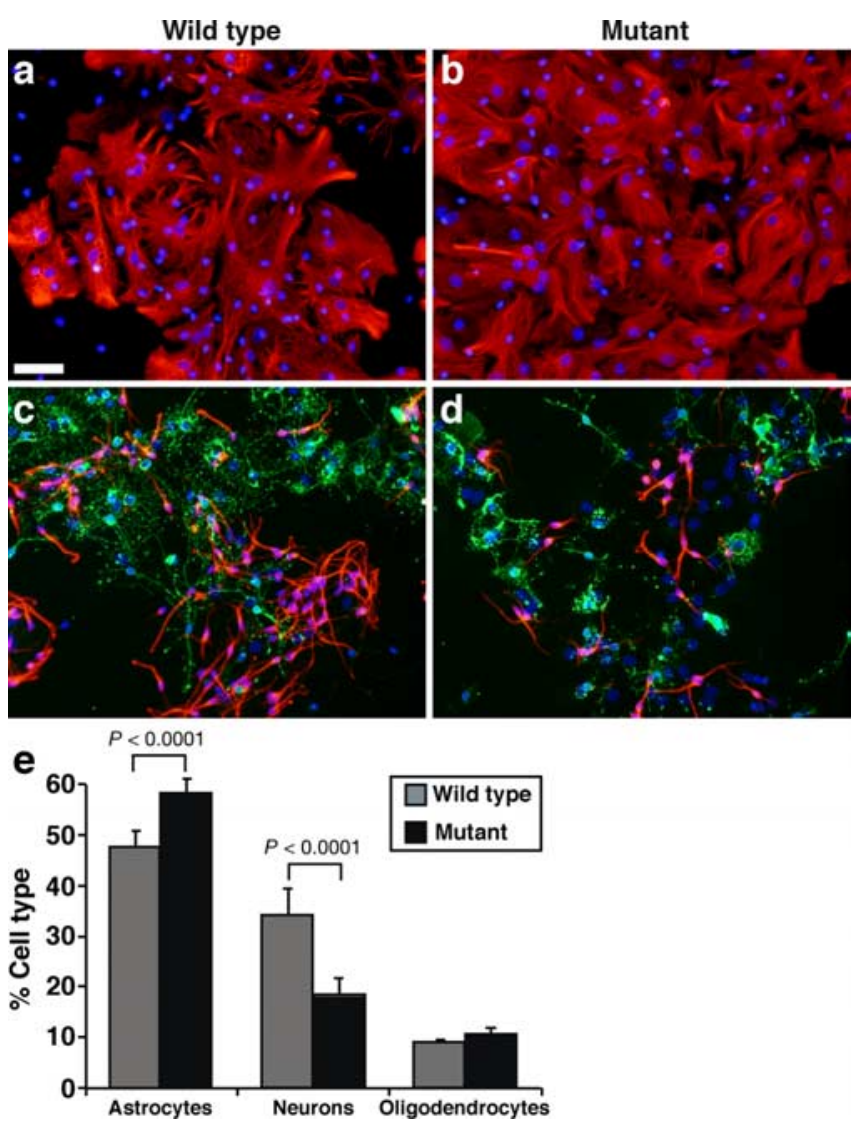

Figure 9. $Q k f^{g t / g t}$ mutant neural precursor cells form fewer neurons in vitro. $\boldsymbol{a}-\boldsymbol{d}$, Cultures of differentiated wild-type $(\boldsymbol{a}, \boldsymbol{c})$ and $Q k^{f t / g t}$ mutant neurosphere cells $(\boldsymbol{b}, \boldsymbol{d})$ stained by immunofluorescence for the astrocyte marker GFAP (red; $\boldsymbol{a}, \boldsymbol{b})$, the neuron marker $\beta$-tubulin type III $(\mathrm{red} ; \boldsymbol{c}, \boldsymbol{d})$, and the oligodendrocyte marker 04 (green; $\boldsymbol{c}, \boldsymbol{d})$, all counterstained with bisbenzimide (blue). SVZ cells were cultured for $7 \mathrm{~d}$ as primary neurospheres, dissociated, and cultured in differentiation conditions on polyornithine/laminin with $1 \%$ fetal bovine serum and without FGF2 and EGF. Cell types were identified based on marker staining and morphology. $\boldsymbol{e}$, Quantification of the percentage of astrocytes, neurons, and oligodendrocytes formed. Note that neurons are formed at a reduced frequency in $Q k^{g t / g t}$ mutant cultures (red; $\boldsymbol{d}$ vs $\boldsymbol{c}$ ) and correspondingly more astrocytes are observed in $Q k^{g t / g t}$ mutant cultures compared with controls $(\boldsymbol{e})$. The change in neuron and astrocyte frequency in $Q k^{f t / g t}$ mutant cultures compared with controls was highly significant $\left(e\right.$ ) (for neurons: $\chi^{2}=697.0, \mathrm{df}=1, p<0.0001, n=$ differentiation cultures from 96 -month-old $Q k f^{9 t / g t}$ mutant and 9 wild-type brains; for astrocytes: $\chi^{2}=$ 122.6, df $=1, p<0.0001, n=$ differentiation cultures from 86 -month-old Qkf ${ }^{g t / g t}$ mutant and 7 wild-type brains). Data are depicted as means \pm SEM, and frequencies of neurons, astrocytes, and oligodendrocytes were analyzed by $\chi^{2}$ test followed by Fisher's post hoc test. Scale bar: $\boldsymbol{a}-\boldsymbol{d}, 50 \mu \mathrm{m}$.

erate normal numbers of interneurons in vitro mirrors the failure of the prenatal $Q k f^{g t / g t}$ brain to generate normal numbers of cortical interneurons (Thomas et al., 2000). Conversely, overexpression of $Q k f$ in vitro leads to an increase in neuron production. These results suggest strongly that normal levels of Qkf are required for the differentiation of neurons, particularly interneurons, in addition to the role of $\mathrm{Qkf}$ in the stem cell compartment.

Unlike in the mature adult $Q k f^{g t / g t}$ mutants, the olfactory bulbs of young $Q k f^{g t / g t}$ mutant animals up to 6 weeks of age appear normal. The majority of interneurons in the olfactory bulb are produced in the postnatal period (Luskin, 1993). The peak olfactory interneuron production is at 3 weeks of age. In young animals, an excess of olfactory interneurons is produced, and excess cells are lost by apoptosis (Mirich et al., 2002). These observations combined with our finding that, at 3 weeks of age, $Q k f^{g t / g t}$ mutant olfactory bulbs are similar to controls suggest
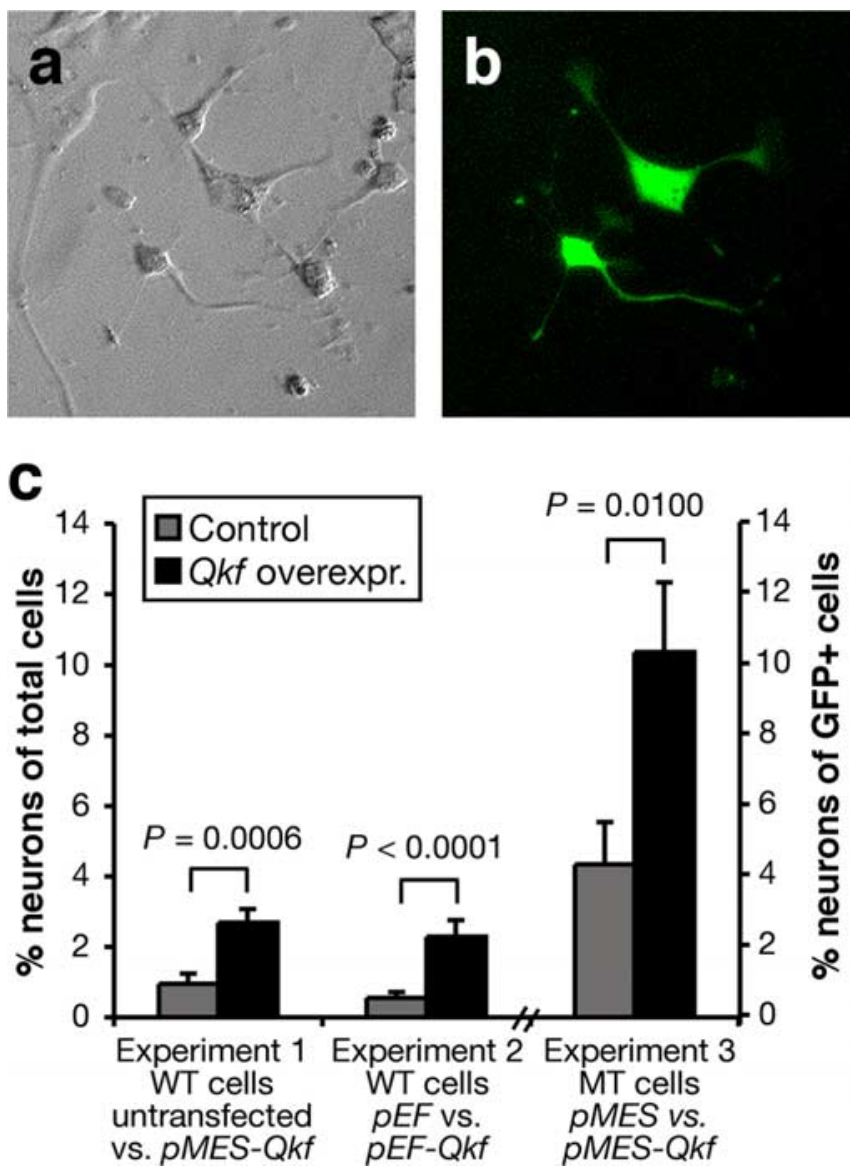

Figure 10. Overexpression of $Q k f$ enhances neuronal production in wild-type neurosphere cells and Qkf ${ }^{g t / g t}$ mutant cells. $\boldsymbol{a}, \boldsymbol{b}$, Cells cultured for $5 \mathrm{~d}$ in differentiation conditions after nucleofection to introduce a GFP expression plasmid showing representative cell types. Differential interference contrast image in $\boldsymbol{a}$ and fluorescence image in $\boldsymbol{b}$. c, Quantification of neuronal differentiation as detected by expression of $\beta$-tubulin type III and neuronal morphology in untransfected neurosphere cells or cells transiently transfected with a bicistronic plasmid expressing $\mathrm{Qkf}$ and GFP ( $p M E S-Q k f), Q k f$ alone ( $p E F-Q k f$ ), empty vector ( $p E F$ ), or vector expression GFP only ( $p M E S$ ). Wild-type cells were used in experiments 1 and 2 and $Q k f^{g t / g t}$ mutant neurosphere cells in experiment 3. Note the significant increase in neuron production in the cultures overexpressing $Q k f$ from $p M E S-Q k f$ over untransfected cells (experiment $1 ; p=$ $0.0006)$, from $p E F-Q k f$ over cells transfected with the empty vector ( $p E F)$ (experiment 2; $p<$ 0.0001 ) and in neurons as percentage of GFP $+Q k f^{g t / g t}$ mutant cells transfected with $p M E S-Q k f$ or control pMES vector (experiment $3 ; p=0.0100$ ). Transfection efficiency was $\sim 24 \%$ and similar in all cultures. Experiments were conducted in duplicate cultures (experiments 1 and 2 ) or in duplicated cultures of three $Q k^{g t / g t}$ mutant neurosphere cell lines (experiment 3). Data are depicted as means \pm SEM and were analyzed by one-factorial ANOVA with plasmid as the independent factor followed by Fisher's post hoc test.

that, initially, there is sufficient capacity to compensate for a reduction in neuronal production in the $Q k f^{g t / g t}$ mutant mice, but that, as the animals age, a reduction in the stem cell output combined with a reduction in the ability of these stem cells to generate neuronal progeny leads to increasingly severe phenotypic effects.

We observed a reduction in the number of neurons produced from Qkf-deficient cells, both in vivo and in vitro. This suggests that $\mathrm{Qkf}$ forms part of the transcriptional machinery regulating neuronal lineage differentiation and that a Qkf-dependent coactivator complex is required to promote neuronal differentiation. In this regard, it is of interest that the $\mathrm{N}-\mathrm{CoR}$ (nuclear corepressor) is required to suppress the astrocytic fate under similar conditions (Hermanson et al., 2002). It has been proposed that coactivators of transcription are required for DNA-binding transcription factors to exert their effects, including the regula- 
tion of differentiation and lineage specification (Mannervik et al., 1999).

Interestingly, the closely related pair of MYST family coactivators, Qkf and Moz, perform corresponding functions in distinct stem cell populations, namely neural stem cells (this study) and hematopoietic stem cells (Katsumoto et al., 2006; Thomas et al., 2006). Moz mutant mice lack hematopoietic stem cells (Thomas et al., 2006). Qkf and Moz heterozygous mutants show intermediate productivity of adult neurogenesis and hematopoiesis, respectively, indicating that $\mathrm{Qkf}$ and Moz levels are limiting the output in the respective stem cell compartment.

In conclusion, we have shown here that normal expression of the $Q k f$ gene is required for two functions during adult neurogenesis, namely for the establishment of the adult NSC population in the SVZ of the lateral ventricles and for the production of normal numbers of olfactory bulb interneurons during adult life.

\section{References}

Berger SL (2002) Histone modifications in transcriptional regulation. Curr Opin Genet Dev 12:142-148.

Champagne N, Bertos NR, Pelletier N, Wang AH, Vezmar M, Yang Y, Heng $\mathrm{HH}$, Yang XJ (1999) Identification of a human histone acetyltransferase related to monocytic leukemia zinc finger protein. J Biol Chem 274:28528-28536.

Coggeshall RE (1992) A consideration of neural counting methods. Trends Neurosci 15:9-13.

Doetsch F, Alvarez-Buylla A (1996) Network of tangential pathways for neuronal migration in adult mammalian brain. Proc Natl Acad Sci USA 93:14895-14900.

Doetsch F, Garcia-Verdugo JM, Alvarez-Buylla A (1997) Cellular composition and three-dimensional organization of the subventricular germinal zone in the adult mammalian brain. J Neurosci 17:5046-5061.

Doetsch F, Caille I, Lim DA, Garcia-Verdugo JM, Alvarez-Buylla A (1999) Subventricular zone astrocytes are neural stem cells in the adult mammalian brain. Cell 97:703-716.

Doetsch F, Petreanu L, Caille I, Garcia-Verdugo JM, Alvarez-Buylla A (2002) EGF converts transit-amplifying neurogenic precursors in the adult brain into multipotent stem cells. Neuron 36:1021-1034.

Gehring WJ, Ikeo K (1999) Pax 6: mastering eye morphogenesis and eye evolution. Trends Genet 15:371-377.

Glass CK, Rosenfeld MG (2000) The coregulator exchange in transcriptional functions of nuclear receptors. Genes Dev 14:121-141.

Hack MA, Saghatelyan A, de Chevigny A, Pfeifer A, Ashery-Padan R, Lledo PM, Gotz M (2005) Neuronal fate determinants of adult olfactory bulb neurogenesis. Nat Neurosci 8:865-872.

Hermanson O, Glass CK, Rosenfeld MG (2002) Nuclear receptor coregulators: multiple modes of modification. Trends Endocrinol Metab 13:55-60.

Hinds JW (1968) Autoradiographic study of histogenesis in the mouse olfactory bulb. I. Time of origin of neurons and neuroglia. J Comp Neurol 134:287-304.

Huang DC, Cory S, Strasser A (1997) Bcl-2, Bcl- $\mathrm{x}_{\mathrm{L}}$ and adenovirus protein E1B19kD are functionally equivalent in their ability to inhibit cell death. Oncogene 14:405-414.

Katsumoto T, Aikawa Y, Iwama A, Ueda S, Ichikawa H, Ochiya T, Kitabayashi I (2006) MOZ is essential for maintenance of hematopoietic stem cells. Genes Dev 20:1321-1330.

Lois C, Alvarez-Buylla A (1994) Long-distance neuronal migration in the adult mammalian brain. Science 264:1145-1148.

Luskin MB (1993) Restricted proliferation and migration of postnatally generated neurons derived from the forebrain subventricular zone. Neuron 11:173-189.

Mannervik M, Nibu Y, Zhang H, Levine M (1999) Transcriptional coregulators in development. Science 284:606-609.
Mirich JM, Williams NC, Berlau DJ, Brunjes PC (2002) Comparative study of aging in the mouse olfactory bulb. J Comp Neurol 454:361-372.

Mombaerts P, Wang F, Dulac C, Chao SK, Nemes A, Mendelsohn M, Edmondson J, Axel R (1996) Visualizing an olfactory sensory map. Cell 87:675-686.

Morshead CM, van der Kooy D (1992) Postmitotic death is the fate of constitutively proliferating cells in the subependymal layer of the adult mouse brain. J Neurosci 12:249-256.

Morshead CM, van der Kooy D (2004) Disguising adult neural stem cells. Curr Opin Neurobiol 14:125-131.

Morshead CM, Reynolds BA, Craig CG, McBurney MW, Staines WA, Morassutti D, Weiss S, van der Kooy D (1994) Neural stem cells in the adult mammalian forebrain: a relatively quiescent subpopulation of subependymal cells. Neuron 13:1071-1082.

Morshead CM, Craig CG, van der Kooy D (1998) In vivo clonal analyses reveal the properties of endogenous neural stem cell proliferation in the adult mammalian forebrain. Development 125:2251-2261.

Nowakowski RS, Lewin SB, Miller MW (1989) Bromodeoxyuridine immunohistochemical determination of the lengths of the cell cycle and the DNA-synthetic phase for an anatomically defined population. J Neurocytol 18:311-318.

O'Rourke NA (1996) Neuronal chain gangs: homotypic contacts support migration into the olfactory bulb. Neuron 16:1061-1064.

Potten CS, Morris RJ (1988) Epithelial stem cells in vivo. J Cell Sci Suppl 10:45-62.

Reynolds BA, Weiss S (1992) Generation of neurons and astrocytes from isolated cells of the adult mammalian central nervous system. Science 255:1707-1710.

Richards LJ, Kilpatrick TJ, Bartlett PF (1992) De novo generation of neuronal cells from the adult mouse brain. Proc Natl Acad Sci USA 89:8591-8595.

Rietze RL, Valcanis H, Brooker GF, Thomas T, Voss AK, Bartlett PF (2001) Purification of a pluripotent neural stem cell from the adult mouse brain. Nature 412:736-739.

Rossi F, Cattaneo E (2002) Opinion: neural stem cell therapy for neurological diseases: dreams and reality. Nat Rev Neurosci 3:401-409.

Simpson TI, Price DJ (2002) Pax6; a pleiotropic player in development. BioEssays 24:1041-1051.

St-Onge L, Sosa-Pineda B, Chowdhury K, Mansouri A, Gruss P (1997) Pax6 is required for differentiation of glucagon-producing alpha-cells in mouse pancreas. Nature 387:406-409.

Swartz ME, Eberhart J, Pasquale EB, Krull CE (2001) EphA4/ephrin-A5 interactions in muscle precursor cell migration in the avian forelimb. Development 128:4669-4680.

Takahashi T, Nowakowski RS, Caviness Jr VS (1992) BUdR as an S-phase marker for quantitative studies of cytokinetic behaviour in the murine cerebral ventricular zone. J Neurocytol 21:185-197.

Thomas T, Dziadek M (1993) Capacity to form choroid plexus-like cells in vitro is restricted to specific regions of the mouse neural ectoderm. Development 117:253-262.

Thomas T, Voss AK, Chowdhury K, Gruss P (2000) Querkopf, a MYST family histone acetyltransferase, is required for normal cerebral cortex development. Development 127:2537-2548.

Thomas T, Corcoran LM, Gugasyan R, Dixon MP, Brodnicki T, Nutt SL, Metcalf D, Voss AK (2006) Monocytic leukemia zinc finger protein is essential for the development of long-term reconstituting hematopoietic stem cells. Genes Dev 20:1175-1186.

Voss AK, Thomas T, Gruss P (1998) Compensation for a gene trap mutation in the murine microtubule-associated protein 4 locus by alternative polyadenylation and alternative splicing. Dev Dyn 212:258-266.

Voss AK, Thomas T, Petrou P, Anastassiadis K, Scholer H, Gruss P (2000) Taube nuss is a novel gene essential for the survival of pluripotent cells of early mouse embryos. Development 127:5449-5461.

Voss AK, Krebs DL, Thomas T (2006) C3G regulates the size of the cerebral cortex neural precursor population. EMBO J 25:3652-3663.

Yang XJ (2004) The diverse superfamily of lysine acetyltransferases and their roles in leukemia and other diseases. Nucleic Acids Res 32:959-976. 